\title{
Calculation of Subgrade Moisture Index in Seasonally Frozen Regions considering Evapotranspiration at Subzero Temperatures and the Pavement Coverage Effect
}

\author{
Dongxue Li $\left(\mathbb{D},{ }^{1}\right.$ Zongyuan Sun, ${ }^{1}$ Jianming Ling, ${ }^{2}$ and Cong $\mathrm{Li}^{3}$ \\ ${ }^{1}$ College of Traffic \& Transportation, Chongqing Jiaotong University, 66 Xuefu Avenue, Chongqing 400074, China \\ ${ }^{2}$ College of Transportation Engineering, Tongii University, 4800 Cao'an Road, Shanghai 201804, China \\ ${ }^{3}$ China Merchants Chongqing Communications Research \& Design Institute Co., Ltd., 33 Xuefu Avenue, \\ Chongqing 400067, China \\ Correspondence should be addressed to Dongxue Li; lidongxue@cqjtu.edu.cn
}

Received 26 November 2020; Revised 23 February 2021; Accepted 27 February 2021; Published 16 March 2021

Academic Editor: Junping Ren

Copyright (C) 2021 Dongxue Li et al. This is an open access article distributed under the Creative Commons Attribution License, which permits unrestricted use, distribution, and reproduction in any medium, provided the original work is properly cited.

\begin{abstract}
The moisture index of subgrade material directly below a paved highway is typically represented by that of an uncovered slope. However, existing studies have demonstrated the existence of a significant moisture content difference between an uncovered slope and covered subgrade owing to evapotranspiration. Moreover, under the influence of solar radiation, wind, and other factors, soil evapotranspiration persists even at subzero temperatures. This paper presents an improved method for subgrade moisture index calculation for regions that freeze seasonally. Instead of the conventional Thornthwaite method, the Food and Agriculture Organization Penman-Monteith (FAO-56 PM) method was employed to estimate the potential evapotranspiration (PE) of slope soil at subzero temperatures. Based on the moisture balance principle, the PE and water runoff and deficit were used as input parameters to calculate the moisture index of an uncovered slope. After the effect of pavement cover on subgrade humidity was defined through a correction coefficient determined via the matric suction dependence of soil water content, an optimized calculation formula was developed to estimate the moisture index of the subgrade material according to that of the corresponding slope. The results calculated on a typical seasonally frozen region in Northeast China demonstrated the applicability and accuracy of the proposed method for predicting the subgrade moisture. The potential evapotranspiration of an uncovered highway slope soil at subzero temperatures could reach $9.8 \%-15.7 \%$ of the total annual evapotranspiration. The moisture index range for seasonally frozen regions was -14.2-57.3. These findings will have important implications for effective improvements in the design and construction of subgrade in regions that freeze seasonally or face similar climatic conditions.
\end{abstract}

\section{Introduction}

While subgrade material is usually unsaturated, its moisture condition is a critical factor that directly affects the strength and stiffness of the pavement structure $[1,2]$. Past studies have shown that the moisture of subgrade material reaches equilibrium several years after construction [3-5]. Thus, the moisture condition is an important consideration in the design of the structure and material of the subgrade.

In China, the moisture index is used to calculate the equilibrium suction of a subgrade when the equilibrium moisture is mainly dependent on the climate [6]. This calculation is commonly performed using the Thornthwaite method, which is based on two concepts: potential evapotranspiration (PE) and moisture balance. However, the Thornthwaite method assumes that the evapotranspiration from the soil ceases when the average temperature is below $0^{\circ} \mathrm{C}$ (i.e., subzero) and the calculated PE is zero [7-10]. The calculation results in the overestimation of the moisture index of the subgrade soil, leading to the adoption of a design value of the subgrade resilience modulus that is significantly high and results in excessive subgrade dehumidification measures. Although the evaporation rate of snow on an exposed subgrade or plant slope (equivalent to bare soil or 
tundra) is lower than that of liquid water and forest cover, it is not zero [11-13]. Thus, the use of the Thornthwaite method to calculate the PE in seasonally frozen areas produces large errors, which reduces the accuracy of the determined moisture index. In recent decades, scholars have developed various PE estimation models that include the use of comprehensive radiation, temperature, and evaporation dish methods [14]. Temperature-based methods depend only on the air temperature and include the Thornthwaite, Hargreaves [15], and McCloud [16] methods.

The most important comprehensive approach for calculating the PE is the Penman-Monteith method, which is recommended by the United Nations Food and Agriculture Organization (FAO) for calculating the daily evapotranspiration of reference crops. The FAO Penman-Monteith (FAO-56 PM) method is the standard technique for calculating the $\mathrm{PE}$ and is used to evaluate other methods in regions lacking adequate measurement data $[17,18]$. FAO56 PM considers five parameters: the maximum air temperature, minimum air temperature, relative humidity, mean wind speed at a height of $2 \mathrm{~m}$, and sunshine hours. The minimum temperature has no limit, which makes the FAO56 method highly accurate and versatile. The Penman equation, which is used to calculate the transpiration forces in China's current Standard of Climatic Zoning for Highway (JTJ 003-1986) [19], is the original form of the FAO-56 PM method. In 1995, Liu et al. used the Penman equation to calculate PE values across China in accordance with the Standard of Climatic Zoning for Highway (JTJ 003-1986) when studying the influence of environmental factors on pavement service performance [20]. In 2017, Li et al. also used the Penman equation to calculate evaporation when predicting the thickness of water and snow (or ice) layers gathered on the pavement surface in Jiangsu Province. The empirical coefficient of the equation was adjusted to align with the actual evaporation in Jiangsu Province [21]. Thus, experts in the transportation field consistently use this method to evaluate the dry and wet conditions of subgrades.

Generally, the Thornthwaite method is employed to calculate the moisture index of the subgrade soil. However, when the subgrade is covered by pavement, which is usually impermeable, the rainfall infiltration and evapotranspiration of the subgrade significantly differ from those of uncovered soil. In the humid and rainy climate of Shanghai, China, a field survey showed that the average moisture content was $23.4 \%$ for slope soil at a depth of $0.5 \mathrm{~m}$ and only $20.3 \%$ for a subgrade located directly beneath a paved highway at the same depth. Thus, the subgrade had a moisture content of approximately 0.87 times that of the slope [22, 23]. Xinjiang, China, experiences strong evapotranspiration, and a field survey showed that the average moisture content was $3.04 \%$ for the exposed surfaces and $5.73 \%$ for the subgrade soil. The subgrade thus had a moisture content of approximately 1.88 times that of the exposed surface [24]. These results indicate that the moisture state of an uncovered slope does not represent that of the subgrade directly below a paved highway.
Although researchers have found that pavement coverage affects the subgrade moisture, current specifications do not provide a quantitative explanation for this phenomenon. Because soil water is generally under motion, it flows from a state of high energy to a state of low energy. However, its seepage velocity is generally slow and the kinetic energy can thus be ignored. Hence, the main factor that determines the movement of soil water is its potential energy [25].

This study aimed to develop a methodology for moisture index calculation of the subgrade in seasonally frozen regions taking into account the $\mathrm{PE}$ and pavement coverage effect. Accurate estimation of the PE is critical for calculating subgrade moisture content. To quantify the evapotranspiration of slope soil at subzero temperatures, which is neglected in the Thornthwaite method, we applied the FAO$56 \mathrm{PM}$ method to predict the PE and evaluated its prediction accuracy with respect to various influencing factors. Then, the moisture index of an uncovered slope was calculated by the moisture balance principle using the PE and two extra factors as input parameters. Based on the matric suction dependence of soil water content, a method for calculating the correction coefficient of the pavement coverage effect was proposed to develop an optimized calculation formula for predicting the subgrade moisture index. The application of the proposed method to a seasonally frozen region in Northeast China was discussed as a case study. This study will not facilitate the exploitation of the subgrade moisture formation mechanism in seasonal freezing regions and other areas with similar climates and therefore establish a targeted method for estimating it, but it can also narrow the existing gap in research on subgrade design and control between seasonally frozen regions and other climatic regions.

\section{Method}

2.1. Calculation of Potential Evapotranspiration (PE) with the FAO-56 PM Method. Evapotranspiration is the amount of water dispersed in the air by evaporation during a certain time period and is typically expressed by the thickness of the evaporated water layer. The FAO-56 PM method considers five parameters: the maximum air temperature, minimum air temperature, relative humidity, mean wind speed at a height of $2 \mathrm{~m}$, and sunshine hours. The calculation formula is as follows:

$$
E T_{0}=\frac{0.408 \Delta\left(R_{n}-G\right)+\gamma(900 /(T+273)) \mu_{2}\left(e_{s}-e_{a}\right)}{\Delta+\gamma\left(1+0.34 u_{2}\right)},
$$

where $E T_{0}$ is the daily evapotranspiration $(\mathrm{cm}), \mathrm{PE}$ is the cumulative $E T_{0}$ after a month, $Z$ and $\varphi$ are the altitude and latitude, respectively, and $T, T_{\max }$, and $T_{\min }$ are the average, maximum, and minimum air temperatures $\left({ }^{\circ} \mathrm{C}\right)$, respectively. Furthermore, $\mathrm{RH}_{\text {mean }}$ denotes the average relative humidity (\%), $n$ represents the actual sunshine hours (h), and $u_{z}$ is the mean wind speed at a height of $2 \mathrm{~m}(\mathrm{~m} / \mathrm{s})$. Moreover, $e_{s}$ and $e_{a}$ are the saturated and actual vapor pressures $(\mathrm{kPa})$, respectively, and are calculated as follows: 


$$
\begin{aligned}
e_{s} & =\frac{e^{0}\left(T_{\max }\right)+e^{0}\left(T_{\min }\right)}{2}, \\
e_{a} & =\frac{R H_{\text {mean }}}{100}\left[\frac{e^{0}\left(T_{\max }\right)+e^{0}\left(T_{\min }\right)}{2}\right], \\
e^{0}(T) & =0.6108 \exp \left(\frac{17.27 T}{T+237.3}\right) .
\end{aligned}
$$

$\Delta$ is the slope of the temperature-saturated vapor pressure curve at $T\left(\mathrm{kPa} /{ }^{\circ} \mathrm{C}\right)$ :

$$
\Delta=\frac{4098(0.6108 \exp (17.27 T /(T+237.3)))}{(T+237.3)^{2}} .
$$

$\gamma$ is the hygrometer constant $\left(\mathrm{kPa} /{ }^{\circ} \mathrm{C}\right)$ :

$$
\gamma=\frac{c_{p} P}{\varepsilon \lambda}=0.665 \times 10^{-3} P,
$$

where $c_{p}$ is the specific heat at a constant pressure and is generally $1.013 \times 10^{-3} \mathrm{MJ} \cdot \mathrm{kg}^{-1} \cdot \mathrm{C}^{-1}$. In addition, $\varepsilon$ is the ratio of water vapor to dry air or latent heat of vaporization and is generally $2.45 \mathrm{MJ} \cdot \mathrm{kg}^{-1}$, and $P$ is the actual local steam pressure:

$$
P=101.3\left(\frac{293-0.0065 Z}{293}\right)^{5.26} .
$$

$R_{n}$ is the net radiation $\left(\mathrm{MJ} \cdot \mathrm{m}^{-2} \cdot \mathrm{d}^{-1}\right)$ :

$$
R_{n}=R_{n s}-R_{n l} .
$$

$R_{n s}$ is the net shortwave radiation $\left(\mathrm{MJ} \cdot \mathrm{m}^{-2} \cdot \mathrm{d}^{-1}\right)$ :

$$
R_{n s}=0.77 R_{s} .
$$

$R_{n l}$ is the net longwave radiation $\left(\mathrm{MJ} \cdot \mathrm{m}^{-2} \cdot \mathrm{d}^{-1}\right)$ :

$$
\begin{aligned}
R_{n l}= & \sigma\left[\frac{T_{\max , K}^{4}+T_{\min , K}^{4}}{2}\right]\left(0.34-0.14 \sqrt{e_{a}}\right) \\
& \left(1.35 \frac{R_{s}}{R_{s 0}}-0.35\right) .
\end{aligned}
$$

$R_{s}$ is the actual solar radiation reaching the Earth's surface $\left(\mathrm{MJ} \cdot \mathrm{m}^{-2} \cdot \mathrm{d}^{-1}\right)$ :

$$
R_{s}=\left(0.25+0.5 \frac{n}{N}\right) R_{a} .
$$

$N$ is the maximum possible sunshine hours (h):

$$
N=\frac{24}{\pi} \omega_{s}
$$

$\omega_{s}$ is the sunshine hour angle (rad):

$$
\omega_{s}=\arccos (-\tan \varphi \tan \delta),
$$

where $\varphi$ and $\delta$ are the latitude and diurnal inclinations ( $\mathrm{rad})$, respectively:

$$
\delta=0.409 \sin \left(\frac{2 \pi}{365} J-1.39\right) .
$$

$J$ is the ordinal number for the day $(J=1$ on January 1 and increments by one for each additional day). $R_{a}$ is the solar radiation at the top of the atmosphere $\left(\mathrm{MJ} \cdot \mathrm{m}^{-2} \cdot \mathrm{d}^{-1}\right)$ :

$$
R_{a}=37.6 d_{r}\left(\omega_{s} \sin \varphi \sin \delta+\cos \varphi \cos \delta \sin \omega_{s}\right),
$$

$d_{r}$ is the reciprocal of the relative distance between the Sun and Earth:

$$
d_{r}=1+0.033 \cos \left(\frac{2 \pi}{365} J\right) .
$$

$R_{\mathrm{so}}$ is the clear sky solar radiation that reaches the Earth's surface $\left(\mathrm{MJ} \cdot \mathrm{m}^{-2} \cdot \mathrm{d}^{-1}\right)$ :

$$
R_{\mathrm{so}}=\left(0.75+\frac{2}{10^{5}} Z\right) R_{a} .
$$

Furthermore, $Z$ is the altitude of the calculated point $(\mathrm{m})$ and $\sigma$ is the Stefan-Boltzmann constant and is given by $\sigma=4.903 \times 10^{-9} \mathrm{MJ} \cdot \mathrm{K}^{-4} \mathrm{~m}^{-2} \mathrm{~d}^{-1} . T_{\max , K}$ and $T_{\min , K}$ are the maximum and minimum absolute temperatures, respectively, where $T_{\max , K}=T_{\text {max }}+273.16 \quad$ and $T_{\min , K}=T_{\min }+273.16$. Meanwhile, $G$ is the soil heat flux and can be generally ignored because it is relatively small on the daily scale, and $u_{z}$ denotes the actual wind speed at the height of the weathervane $\left(\mathrm{m} \cdot \mathrm{s}^{-1}\right)$ :

$$
u_{2}=u_{z} \frac{4.87}{\ln (67.8 z-5.42)} \text {. }
$$

\subsection{Principle of Moisture Balance and Moisture Index of Slope} Soil. Moisture balance is a concept used in soil science and agricultural meteorology. Common models include the exponential regression model, artificial neural network model, water balance model, soil water and heat-coupling transport model for a freezing-thawing period, and soilplant-atmosphere continuum water and heat-coupling transport model $[26,27]$. The Thornthwaite method uses the water balance model to determine the moisture balance. $\mathrm{Li}$ et al. [28] calculated the potential vegetation productivity in China using a dynamic soil moisture model based on the Thornthwaite method. The Thornthwaite moisture balance principle has been applied to subgrade moisture balance analysis $[9,29,30]$.

The soil has a certain water storage capacity because of its complex porous structure. Water is replenished by meteorological precipitation and lost through evapotranspiration. When the precipitation is less than the evapotranspiration, all the precipitation will be evaporated, along with part of the original water in the soil. After all the original moisture in the soil evaporates, the soil assumes the deficit (DF) state. When the precipitation is greater than the PE, the soil reaches the maximum moisture state (i.e., saturated). The excess precipitation flows away in the form of runoff, and $R$ represents the total amount of runoff produced in a month. In the following calculation, the month is used as the statistical unit. The moisture balance of the soil can be summarized by the following three states distinguished by the monthly storage of soil moisture: 


\section{$\left\{\begin{array}{l}\text { 1. Existing Runoff, } \\ \text { 2. No Runoff and No Drought, } \\ \text { 3. No Runoff but Drought, }\end{array}\right.$}

where $S_{i}$ is the monthly water storage $(\mathrm{cm})$ for month $i$ and $S_{\max }$ is the maximum soil water storage capacity $(\mathrm{cm})$. In state $1, S_{i}>S_{\max }$, the monthly storage exceeds the maximum capacity, and not all of the water has evaporated in the current month. The surplus water can form runoff to replenish the soil in the next month. In state $2,0<S_{i} \leq S_{\max }$, the monthly storage is between zero and the maximum capacity. Not all the water has evaporated in the current month; however, runoff does not form to replenish the soil in the next month. In state $3, S_{i} \leq 0$, the monthly water storage is zero and all the water (including the monthly precipitation and the supply of the prior month) has evaporated in the current month. It should be noted that no practical condition exists in which the soil water storage is less than zero. This finding is only the result of a mathematical calculation indicating that the evaporation in the current month is much greater than the precipitation. Based on the above analysis, the calculation process of the moisture balance was optimized to that shown in Figure 1.

$S_{i-1}$ represents the final water storage of the soil in the previous month, which is the initial water storage of the current month. The maximum storage capacity $S_{\max }$ depends on the soil type and is equal to the product of the saturated volumetric moisture content $\theta_{s}$ and thickness of the soil layer $h$. The influence of the rainfall depth is generally between 0.6 and $2.5 \mathrm{~m} \mathrm{[31].}$

In this study, the soil layer thickness $h$ of a slope affected by rainfall was set to $1.2 \mathrm{~m}$ [31]. To calculate the moisture balance, the initial water storage capacity $S_{0}$ of the slope soil needs to be determined. The initial water storage is related to the initial moisture conditions of the soil and is equal to the initial moisture content $\theta_{0}$ multiplied by the thickness of the soil layer $h$ (i.e., $1.2 \mathrm{~m}$ ). The moisture index is an annual index and is calculated from the moisture balance of the annual monthly precipitation and PE. The moisture index of the slope soil $\left(I_{m}^{\prime}\right)$ is given by

$$
I_{m}^{\prime}=\frac{100\left(R_{y}\right)-60\left(\mathrm{DF}_{y}\right)}{\left(\mathrm{PE}_{y}\right)},
$$

where $R_{y}$ is the annual runoff $(\mathrm{cm})$ of the slope soil and $\mathrm{DF}_{y}$ is the annual water deficit $(\mathrm{cm})$ of the slope soil. $\mathrm{PE}_{y}$ is the annual total evapotranspiration $(\mathrm{cm})$ of the slope soil. The above values are obtained by the accumulation of the monthly values.

2.3. Correction Coefficient for the Pavement Coverage Effect. Because the pavement material is usually impermeable, the moisture in the subgrade directly below undamaged pavement cannot evaporate as freely as that on natural ground.
$S_{i}>S_{\max }$

$0<S_{i}<S_{\max }, i=1,2, \ldots, 12$,

$S_{i} \leq 0$

This is referred to as the pavement coverage effect. Evapotranspiration and infiltration cannot be accurately measured in the subgrade; thus, the subgrade moisture index cannot be directly calculated with equation (18). The pavement coverage effect hinders not only the transpiration of moisture in the subgrade, but also the direct infiltration of natural precipitation. When groundwater is deeply buried, the subgrade moisture is not affected by changes in the groundwater level, and the infiltration of capillary water rises. In this case, the water supply to the subgrade and the water loss from the subgrade are mainly caused by the precipitation infiltration and evapotranspiration of the slope soil. The moisture transfer force between the slope soil and subgrade is known as the matric suction force. This factor is used to establish a method for calculating the correction coefficient for pavement coverage. This method is employed to modify the moisture index of the slope soil. Accordingly, the moisture index of the subgrade can be obtained.

For a dry subgrade with a working area above the capillary wetting surface of groundwater, the subgrade moisture is not affected by the groundwater. When energy loss and longitudinal seepage flow are not considered, the subgrade moisture index $\left(I_{m}\right)$ is directly proportional to the slope soil moisture index $\left(I_{m}^{\prime}\right)$ and is closely related to the pavement coverage effect:

$$
I_{m} \propto I_{m}^{\prime}
$$

This can be expressed as

$$
I_{m}=c \times I_{m}^{\prime}
$$

where $c$ is the correction coefficient for the pavement coverage effect.

According to soil mechanics, water always flows from a state of high energy to a state of low energy, as previously mentioned. The potential energy determines the movement of water in soil; it can be divided into the gravity, pressure, matrix, and solute potentials. For unsaturated soils without salinization, the potential energy mainly comprises the gravity and matrix potentials. If the vertical distance between two points under consideration (i.e., slope soil and subgrade) is zero, then the gravity potential would be zero. The matrix potential $\Psi_{m}$ is mainly caused by the surface tension of the air-water interface in unsaturated soil and is calculated as

$$
\Psi_{m}=-s=-\left(u_{a}-u_{w}\right) .
$$

When a pore is connected to the atmosphere, then $u_{a}=p_{a}=0 . u_{w}$ is the negative pore water pressure, and $s$ is the matric suction. Therefore, the main factor that causes water movement between the slope soil and the subgrade is the matric suction between them. The pavement coverage 


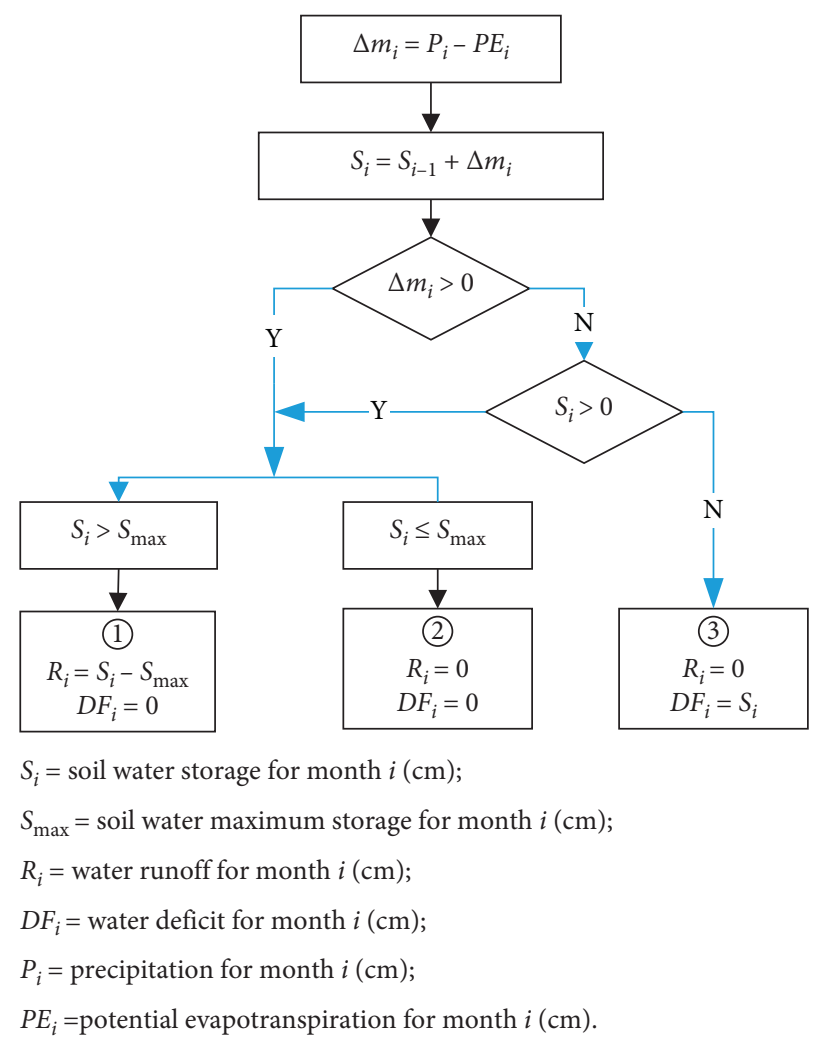

Figure 1: Moisture balance calculation process.

correction coefficient $c$ can be defined as the ratio of the matric suctions of the slope soil and subgrade:

$$
c=\frac{s_{s w}}{s_{s s}}
$$

where $s_{s w}$ is the matric suction of a certain point in the subgrade and $s_{s s}$ is the matric suction at a point in the slope soil at the same height. For unsaturated soils, the soil-water characteristic curve (SWCC) describes the relationship between the matric suction and the humidity. It is also used to estimate the dynamic resilience modulus and permanent deformation of the subgrade. For a given soil, the SWCC is monotonic within its defined interval. Therefore,

$$
c=\frac{s_{s w}}{s_{s s}}=\frac{\theta_{s w}}{\theta_{s s}}
$$

where $\theta_{\text {sw }}$ is the volume moisture content of the subgrade and is equal to the optimal volume moisture content of the subgrade $\theta_{0} . \theta_{\text {ss }}$ is the volume moisture content of the slope soil and is calculated according to the water stored in a unit volume of the slope soil at the end of the year:

$$
\theta_{s s}=\frac{S_{y}}{h}
$$

where $h$ is the calculated thickness of the slope $(h=1.2 \mathrm{~m})$ and $S_{y}$ is the final value of the annual water storage:

$$
\theta_{s s}=\left|\frac{R_{y}-0.6 \mathrm{DF}_{y}}{h}\right|=\frac{S_{y}}{h} .
$$

When $\left(R_{y}-0.6 \mathrm{DF}_{y}\right) / h>0, R_{\mathrm{y}}$ is greater than the corresponding $\mathrm{DF}_{y}$ for a given year, and the slope soil has more moisture than the initial state; then, $I_{m}^{\prime}$ is positive. When $\left(R_{y}-0.6 \mathrm{DF}_{y}\right) / h<0, R_{\mathrm{y}}$ is less than the corresponding $\mathrm{DF}_{y}$ for a given year and the slope soil contains less moisture than in the initial state, and $I_{m}^{\prime}$ is negative. Depending on the positive and negative conditions of $I_{m}^{\prime}, c$ can be calculated as follows:

$$
\begin{cases}c=\frac{\theta_{s w}}{\theta_{s s}}=\frac{\theta_{0}}{\left(R_{y}-0.6 D F_{y}\right) / h}, & I_{m}^{\prime}>0, \\ c=\frac{\theta_{s s}}{\theta_{s w}}=\frac{\left|\left(R_{y}-0.6 D F_{y}\right) / h\right|}{\theta_{0}-\left|\left(R_{y}-0.6 D F_{y}\right) / h\right|}, & I_{m}^{\prime} \leq 0 .\end{cases}
$$

2.4. Moisture Index $\left(I_{m}\right)$ Calculation Example. As an example, the FAO-56 PM method was used to calculate the PE at the Yanji Meteorological Station (YJ). The basic information of the meteorological stations is presented in Table 1. The initial volumetric moisture content $\theta_{0}$ was 0.18 , and the saturated volumetric moisture content $\theta_{s}$ was 0.24 . The meteorological data were obtained from the monthly datasets of the surface climatic standard values (1971-2000) published by the China Meteorological Administration, as given in Table 2. The PE calculation process is presented in Table 3. The calculation process and results for the moisture balance and slope soil moisture index $I_{m}^{\prime}$ are presented in 
TABLE 1: Meteorological station information.

\begin{tabular}{lccc}
\hline Longitude & Latitude & Meteorological station & Elevation \\
\hline $126.28^{\circ} \mathrm{E}$ & $42.53^{\circ} \mathrm{N}$ & $\mathrm{YJ}$ & $176.8 \mathrm{~m}$ \\
\hline
\end{tabular}

TABLe 2: Meteorological station data.

\begin{tabular}{lccccc}
\hline Month & $T_{\max }\left({ }^{\circ} \mathrm{C}\right)$ & $T_{\min }\left({ }^{\circ} \mathrm{C}\right)$ & $R H_{\text {mean }}(1 \%)$ & $u_{z}(\mathrm{~m} / \mathrm{s})$ & $N(\mathrm{~h})$ \\
\hline 1 & -6.5 & -19.4 & 59.0 & 2.6 & 170.4 \\
2 & -2.2 & -16.0 & 55.0 & 2.8 & 183.2 \\
3 & 5.6 & -8.2 & 53.0 & 2.9 & 225.3 \\
4 & 15.1 & -0.1 & 55.0 & 3.1 & 213.2 \\
5 & 21.5 & 6.7 & 60.0 & 2.8 & 233.6 \\
6 & 24.0 & 12.9 & 75.0 & 2.4 & 190.0 \\
7 & 27.1 & 17.2 & 79.0 & 2.2 & 181.0 \\
8 & 26.9 & 17.1 & 80.0 & 1.8 & 187.5 \\
9 & 21.9 & 9.1 & 77.0 & 1.6 & 197.6 \\
10 & 14.5 & 0.3 & 67.0 & 2.1 & 199.5 \\
11 & 3.9 & -8.0 & 62.0 & 2.5 & 157.7 \\
12 & -4.3 & -16.2 & 61.0 & 2.5 & 140.8 \\
\hline
\end{tabular}

TABLE 3: PE calculation process.

\begin{tabular}{lccccccc}
\hline Month & $e_{s}$ & $\Delta$ & $e_{a}$ & $R_{n}$ & $\gamma$ & $u_{2}$ & PE (cm) \\
\hline 1 & 0.25 & 0.02 & 0.15 & 2.60 & 0.07 & 1.94 & 1.37 \\
2 & 0.35 & 0.02 & 0.19 & 2.56 & 0.07 & 2.09 & 2.21 \\
3 & 0.62 & 0.04 & 0.33 & 8.31 & 0.07 & 2.17 & 4.97 \\
4 & 1.16 & 0.07 & 0.64 & 8.34 & 0.07 & 2.32 & 8.55 \\
5 & 1.77 & 0.10 & 1.06 & 12.34 & 0.07 & 2.09 & 11.76 \\
6 & 2.24 & 0.13 & 1.68 & 11.99 & 0.07 & 1.80 & 10.91 \\
7 & 2.77 & 0.16 & 2.19 & 11.26 & 0.07 & 1.65 & 11.44 \\
8 & 2.75 & 0.16 & 2.20 & 11.38 & 0.07 & 1.35 & 10.25 \\
9 & 1.89 & 0.11 & 1.46 & 6.75 & 0.07 & 1.20 & 7.03 \\
10 & 1.89 & 0.11 & 1.27 & 6.37 & 0.07 & 1.57 & 6.36 \\
11 & 0.57 & 0.04 & 0.35 & 1.16 & 0.07 & 1.87 & 2.44 \\
12 & 0.31 & 0.02 & 0.19 & 1.35 & 0.07 & 1.87 & 1.40 \\
\hline
\end{tabular}

Table 4 . The pavement coverage correction coefficient $c$ was determined to be

$$
c=\frac{\theta_{s s}}{\theta_{s w}}=\frac{\left|\left(R_{y}-0.6 D F_{y}\right) / h\right|}{\theta_{0}-\left|\left(R_{y}-0.6 D F_{y}\right) / h\right|}=\frac{0.0495}{0.18-0.0495}=0.38 \text {. }
$$

Thus, the annual moisture index of the subgrade was

$$
I_{m}=c \times I_{m}^{\prime}=0.38 \times(-7.55)=-2.86 .
$$

\section{Data}

Currently, the Standard of Climatic Zoning for Highway classifies the eastern Changbai Mountains in Northeast China as Zone $\mathrm{II}_{1}$. This area is distributed over Heilongjiang, Jilin, and Liaoning Provinces and is a typical example of a seasonally frozen area. Highway projects in this area are mainly threatened by snow damage in winter and water damage in summer. The moisture index for the slope soil in this area was calculated using the FAO-56 PM method, and $c$
TABLE 4: Moisture balance calculation data.

\begin{tabular}{lcccccc}
\hline Month & $\begin{array}{c}P_{i} \\
(\mathrm{~cm})\end{array}$ & $\begin{array}{c}\mathrm{PE}_{i} \\
(\mathrm{~cm})\end{array}$ & $\begin{array}{c}\Delta m_{i} \\
(\mathrm{~cm})\end{array}$ & $\begin{array}{c}S_{i}(\mathrm{~cm}) / d_{i} \\
(\mathrm{~cm})\end{array}$ & $\begin{array}{c}R_{i} \\
(\mathrm{~cm})\end{array}$ & $\begin{array}{c}D F_{i} \\
(\mathrm{~cm})\end{array}$ \\
\hline 1 & 0.37 & 1.37 & -1.00 & 20.60 & 0 & 0 \\
2 & 0.52 & 2.21 & -1.69 & 18.91 & 0 & 0 \\
3 & 0.83 & 4.97 & -4.14 & 14.77 & 0 & 0 \\
4 & 2.52 & 8.55 & -6.03 & 8.74 & 0 & 0 \\
5 & 5.40 & 11.76 & -6.36 & 2.38 & 0 & 0 \\
6 & 8.88 & 10.91 & -2.03 & 0.36 & 0 & 0 \\
7 & 11.53 & 11.44 & 0.09 & 0.44 & 0 & 0 \\
8 & 12.19 & 10.25 & 1.94 & 2.38 & 0 & 0 \\
9 & 6.41 & 7.03 & -0.62 & 1.76 & 0 & 0 \\
10 & 2.46 & 6.36 & -3.90 & -2.14 & 0 & 2.14 \\
11 & 1.08 & 2.44 & -1.36 & -3.50 & 0 & 3.50 \\
12 & 0.64 & 1.40 & -0.76 & -4.26 & 0 & 4.26 \\
Total & - & 78.69 & - & - & 0 & 9.90 \\
$I_{m}^{\prime}$ & \multicolumn{7}{c}{-7.55} \\
\multicolumn{7}{c}{$S_{0}=$} \\
\hline
\end{tabular}

was calculated using equation (26). The moisture index for the typical subgrade in the area was then calculated.

The meteorological data used here were obtained from the monthly datasets of the surface climatic standard values published by the China Meteorological Administration (1971-2000). The China Meteorological Data Network provides detailed data at http://data.cma.cn. Table 5 presents the values of $\theta_{0}$ and $\theta_{\mathrm{s}}$ for different soil groups.

\section{Results and Discussion}

4.1. Correlation Analysis between the Potential Evapotranspiration (PE) and Meteorological Factors. Table 6 presents the PE values calculated for the different stations. Evapotranspiration occurred in the slope soils at subzero temperatures, which lasted for 3-5 months. The PE accounted for $9.8 \%-15.7 \%$ of the total evapotranspiration at subzero temperatures.

4.1.1. Mean Sunshine Hours. Figure 2 shows the relationship between PE and mean sunshine hours of seven meteorological stations. The relationship between PE and the mean sunshine hours at subzero temperatures is depicted in Figure 3. Table 7 presents the correlation coefficient between $\mathrm{PE}$ and mean sunshine hours. The results indicate that the mean sunshine hours had a significant influence on the evapotranspiration of the subgrade, as shown in Figure 2. When the annual data were used for the statistical analysis, PE showed an increasing trend at the seven meteorological stations with an average rate of increase of $0.08 \mathrm{~cm} / \mathrm{h}$ and an average correlation coefficient of 0.65 , as shown in Table 7 .

When only subzero temperature data were used (i.e., the average temperature was less than $0^{\circ} \mathrm{C}$ ), the mean sunshine hours showed a significant positive correlation with the evapotranspiration of the subgrade, as illustrated in Figure 3. At subzero temperatures, the mean sunshine hours were 136.8-244.1 h, while the PE values were within $0.69-4.97 \mathrm{~cm}$. PE increased significantly with increasing sunshine hours, 
TABLe 5: Characteristic values of the volumetric water contents of different soil types [32].

\begin{tabular}{lcccc}
\hline Soil group & Sand & Other sandy soils & Powdery soil & Clayey soil \\
\hline$\theta_{s}$ & 0.24 & 0.29 & 0.33 & 0.37 \\
$\theta_{0}$ & 0.18 & 0.20 & 0.28 & 0.34 \\
\hline
\end{tabular}

TABLE 6: PE values for different soil types in Zone $\mathrm{II}_{1}(\mathrm{~cm})$.

\begin{tabular}{|c|c|c|c|c|c|c|c|}
\hline \multirow[b]{2}{*}{ Month } & \multicolumn{7}{|c|}{ Meteorological station } \\
\hline & $\begin{array}{l}\text { Suifenhe } \\
(\mathrm{SFH})\end{array}$ & $\begin{array}{l}\text { Mudanjiang } \\
(\mathrm{MDJ})\end{array}$ & $\begin{array}{l}\text { Jixi } \\
\text { (JX) }\end{array}$ & $\begin{array}{l}\text { Linjiang } \\
(\mathrm{LJ})\end{array}$ & $\begin{array}{l}\text { Yanji } \\
(\mathrm{YJ})\end{array}$ & $\begin{array}{c}\text { Dandong } \\
\text { (DD) }\end{array}$ & $\begin{array}{c}\text { Benxi } \\
(\mathrm{BX})\end{array}$ \\
\hline 1 & 1.05 & 0.75 & 1.02 & 0.69 & 1.37 & 2.47 & 1.42 \\
\hline 2 & 1.62 & 1.47 & 1.74 & 1.49 & 2.21 & 3.33 & 2.34 \\
\hline 3 & 4.01 & 4.36 & 4.55 & 4.20 & 4.97 & 5.64 & 5.47 \\
\hline 4 & 7.90 & 8.51 & 8.78 & 7.85 & 8.55 & 8.33 & 10.04 \\
\hline 5 & 11.03 & 12.24 & 12.75 & 10.77 & 11.76 & 10.93 & 13.26 \\
\hline 6 & 10.40 & 12.27 & 12.37 & 11.35 & 10.91 & 11.12 & 13.29 \\
\hline 7 & 10.97 & 12.55 & 12.72 & 11.56 & 11.44 & 10.40 & 12.32 \\
\hline 8 & 9.63 & 10.70 & 10.70 & 10.00 & 10.25 & 10.74 & 10.93 \\
\hline 9 & 6.80 & 7.31 & 7.64 & 6.61 & 7.03 & 8.70 & 8.27 \\
\hline 10 & 5.04 & 4.61 & 5.28 & 4.20 & 6.36 & 6.26 & 5.74 \\
\hline 11 & 2.33 & 1.93 & 2.30 & 1.71 & 2.44 & 3.65 & 2.75 \\
\hline 12 & 1.19 & 0.80 & 1.07 & 0.70 & 1.40 & 2.47 & 1.55 \\
\hline Total PE at subzero temperature & 10.20 & 9.32 & 10.68 & 8.80 & 12.39 & 8.27 & 10.78 \\
\hline Total PE at mean annual temperature & 71.97 & 77.50 & 80.93 & 71.14 & 78.69 & 84.03 & 87.37 \\
\hline $\begin{array}{l}\text { Proportion of PE at subzero } \\
\text { temperature }(\%)\end{array}$ & 14.2 & 12.0 & 13.2 & 12.4 & 15.7 & 9.8 & 12.3 \\
\hline
\end{tabular}
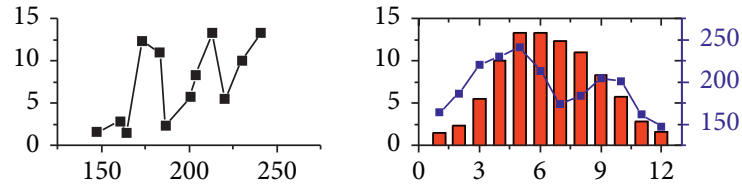

(1) BX
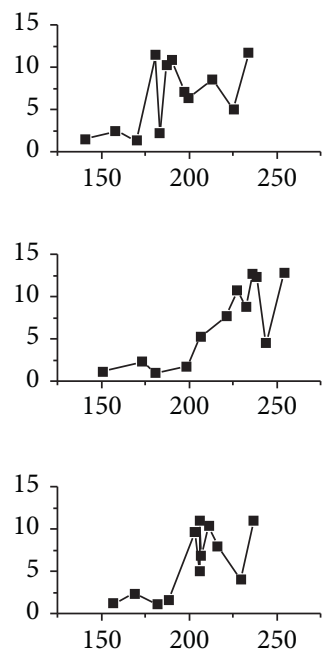

Mean sunshine hours (h)

(7) $\mathrm{SFH}$

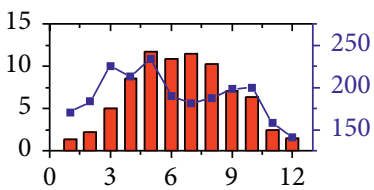

(3) $\mathrm{Y}$

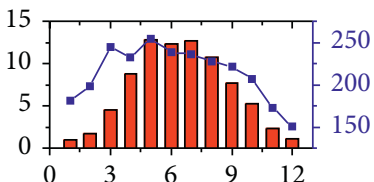

(5) JX

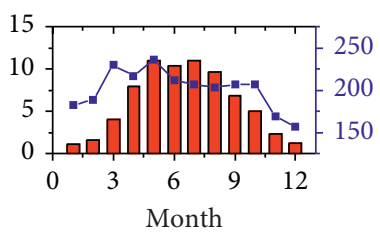

$\begin{aligned} \mathrm{PE} & \longrightarrow \mathrm{PE} \\ & \longrightarrow \mathrm{MSH}\end{aligned}$

(a) (b)
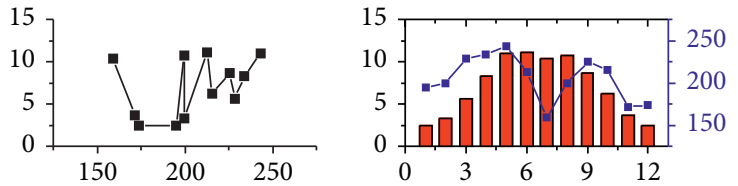

(2) DD
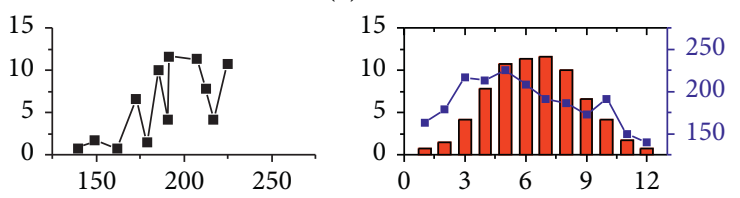

(4) LJ
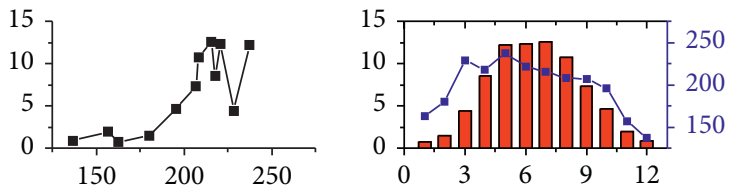

(6) $\mathrm{MDJ}$
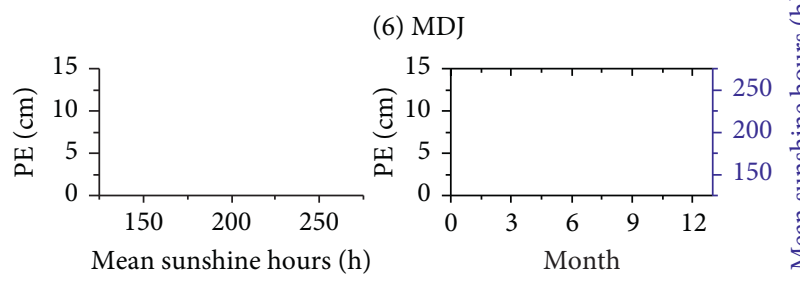

$\square \mathrm{PE}$

$\because \mathrm{MSH}$

(b)

FIGURE 2: Correlation between the PE and mean sunshine hours of seven reference meteorological stations. (a) PE as a function of mean sunshine hours. (b) PE and mean sunshine hours as a function of months. 


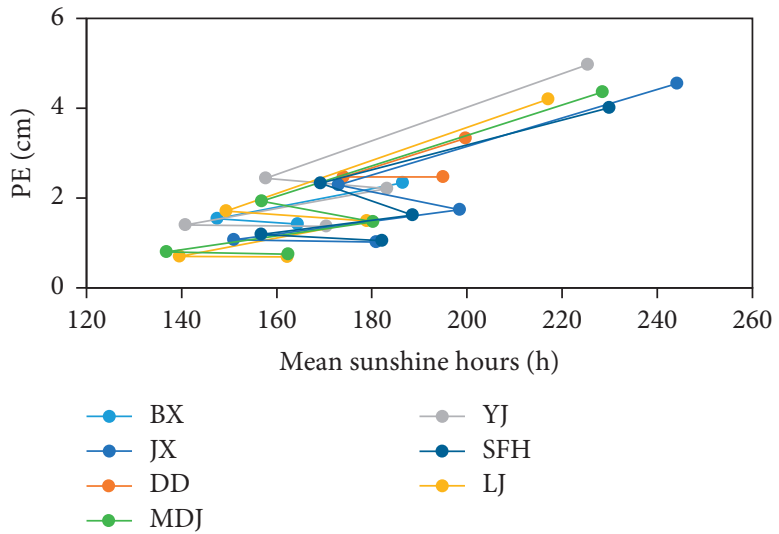

Figure 3: Relationship between PE and mean sunshine hours at subzero temperatures.

TABle 7: Pearson correlation coefficient (mean sunshine hours).

\begin{tabular}{|c|c|c|c|c|c|c|c|c|}
\hline & \multicolumn{7}{|c|}{ Meteorological station } & \multirow{2}{*}{ Mean value } \\
\hline & $\mathrm{BX}$ & $\mathrm{DD}$ & YJ & LJ & $\mathrm{JX}$ & MDJ & SFH & \\
\hline Analysis with annual temperature data & 0.62 & 0.35 & 0.58 & 0.68 & 0.83 & 0.81 & 0.7 & 0.65 \\
\hline Analysis with subzero temperature data & 0.84 & 0.64 & 0.88 & 0.88 & 0.87 & 0.90 & 0.81 & 0.83 \\
\hline
\end{tabular}

with an average rate of increase of $0.03 \mathrm{~cm} / \mathrm{h}$ and an average correlation coefficient of 0.83 , as shown in Table 7 .

4.1.2. Mean Wind Speed. Figure 4 shows the relationship between $\mathrm{PE}$ and the mean wind speed, while Figure 5 shows the relationship between $\mathrm{PE}$ and the mean wind speed at subzero temperatures. Table 8 presents the correlation coefficient between PE and the mean wind speed. The results indicate that, over the course of a year, the monthly averaged $\mathrm{PE}$ variation with respect to the mean wind speed did not show a consistent trend among the stations, as shown in Figure 4. PE showed a decreasing trend at DD and SFH, with correlation coefficients of -0.85 and -0.8 , respectively. JX and YJ also had negative correlations; however, the correlation coefficients were only -0.54 and -0.23 , respectively, as shown in Table 8. PE showed an increasing trend with the mean wind speed at the other stations, as depicted in Figure 5. LJ showed a clear increasing trend with a correlation coefficient of 0.56 , while BX and MDJ had correlation coefficients of only 0.04 and 0.09 , respectively. For subzero mean temperatures, the mean wind speed was found to have a significant positive correlation with $\mathrm{PE}$ of the slope soil among all stations, with the exception of SFH. In general, the mean wind speed was $0.7-3.0 \mathrm{~m} / \mathrm{s}$ for subzero temperatures, and PE was $0.69-4.97 \mathrm{~cm}$. PE showed a rate of increase of $5.15 \mathrm{~cm} /(\mathrm{m} / \mathrm{s})$, and the average correlation coefficient was 0.81 . For $\mathrm{SFH}$, the multiyear mean wind speed decreased monthly, which was completely opposite to the trend at other stations in Zone $\mathrm{II}_{1}$. Hence, when the value of PE at SFH was calculated using the FAO-56 PM method, it was negatively correlated with the mean wind speed, yielding a correlation coefficient of -0.91 , as shown in Table 8 .
4.1.3. Mean Temperature. Figure 6 shows the relationship between the mean temperature and PE, while Figure 7 shows the relationship between $\mathrm{PE}$ and the mean temperature at subzero temperatures. Table 9 presents the correlation coefficient between PE and the mean temperature. The results indicate that the mean temperature had a significant effect on the evapotranspiration of the slope soil, as shown in Figure 6. Over the entire year, PE increased with the mean temperature at the seven meteorological stations with an average rate of increase of $0.31 \mathrm{~cm} /{ }^{\circ} \mathrm{C}$ and an average correlation coefficient of 0.94 , as presented in Table 9 . At subzero temperatures, the mean temperature showed a significant positive correlation with the evapotranspiration of the slope soil, as depicted in Figure 7 . In Zone $\mathrm{II}_{1}$, subzero temperatures last approximately 3-5 months. At subzero temperatures, $\mathrm{PE}$ was $0.69-4.97 \mathrm{~cm}$ with an average rate of increase of $0.19 \mathrm{~cm} /{ }^{\circ} \mathrm{C}$, and the average correlation coefficient was 0.79 at JX, as shown in Table 9.

4.1.4. Mean Relative Humidity. Figure 8 shows the relationship between the mean relative humidity and PE at the seven meteorological stations. Figure 9 depicts the relationship between $\mathrm{PE}$ and the mean relative humidity at subzero temperatures. Table 10 presents the correlation coefficient between $\mathrm{PE}$ and the mean relative humidity. The results and analysis of the annual data showed that the mean relative humidity did not have a significant effect on the evapotranspiration of the slope soil, as shown in Figure 8. PE showed no clear trends at the seven meteorological stations. At DD and YJ, there was a relatively linear increase in PE with the relative humidity, with correlation coefficients of 0.57 and 0.89 , respectively. In contrast, the other five stations 

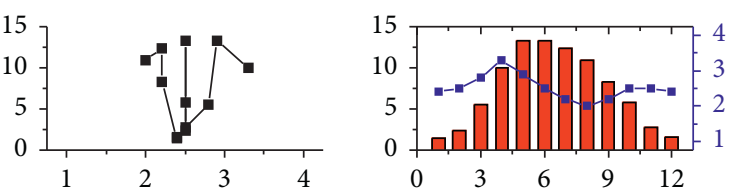

(1) BX
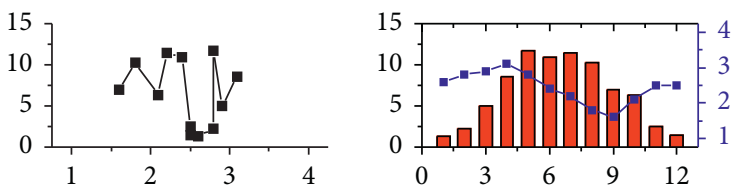

(3) $\mathrm{Y}$
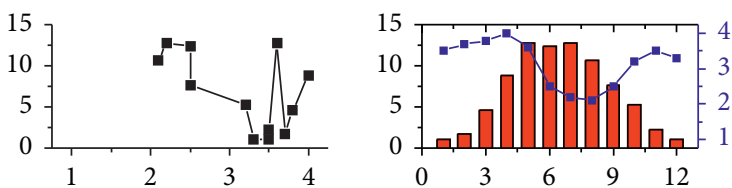

(5) JX
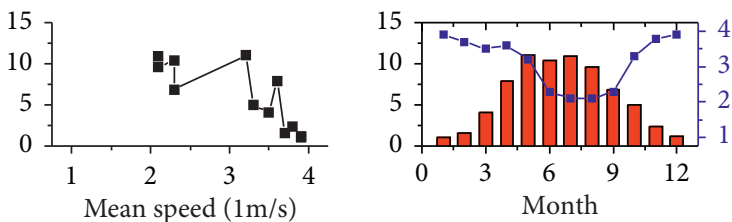

(7) $\mathrm{SFH}$

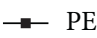

(a)

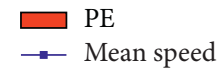

(b)
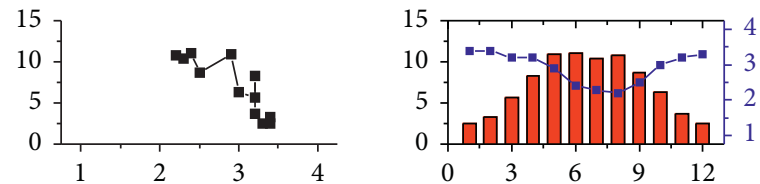

(2) DD
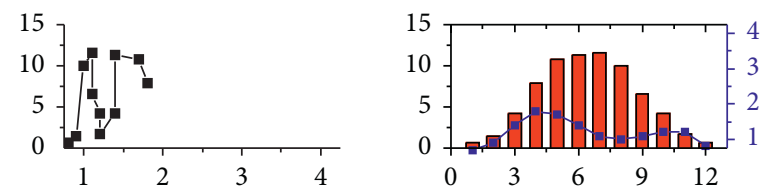

(4) JL
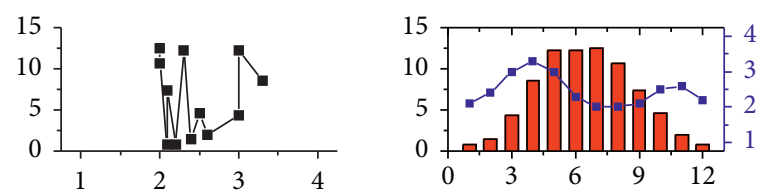

(6) MDJ
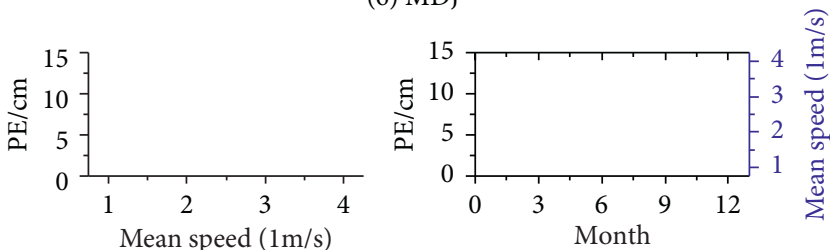

$\square \mathrm{PE}$

(a)

(b)

FIgURE 4: Correlation between the PE and mean wind speed of seven reference meteorological stations. (a) PE as a function of mean wind speed. (b) PE and mean wind speed as a function of months.

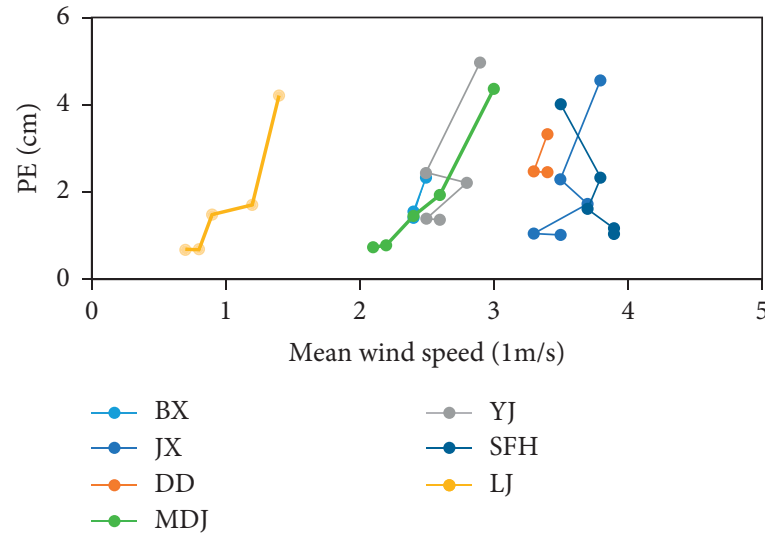

FIGURE 5: Relationship between PE and mean wind speed for subzero temperatures.

TABle 8: Pearson correlation coefficient (mean wind speed).

\begin{tabular}{lcccccccc}
\hline & \multicolumn{4}{c}{ Meteorological station } & \multicolumn{3}{c}{ Mean value } \\
& BX & DD & YJ & LJ & JX & MDJ & SFH & \\
\hline Analysis with annual temperature data & 0.09 & -0.85 & -0.23 & 0.56 & -0.54 & 0.04 & -0.80 & -0.25 \\
Analysis with subzero temperature data & 0.99 & 0.49 & 0.75 & 0.91 & 0.76 & 0.97 & -0.91 & 0.81 \\
\hline
\end{tabular}

had correlation coefficients that were less than 0.5 with an average of 0.26 , as presented in Table 10 . When the mean temperature was subzero, the results showed that the mean relative humidity had a significant negative correlation with the evapotranspiration of the slope soil, as shown in Figure 9. When the mean temperature was subzero, the mean relative humidity of the seven meteorological stations ranged from $53 \%$ to $73 \%$, and the PE values were within $0.69-4.97 \mathrm{~cm}$. PE 

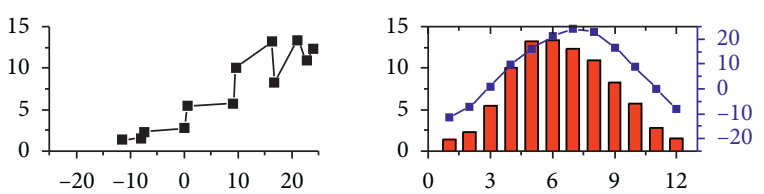

(1) BX
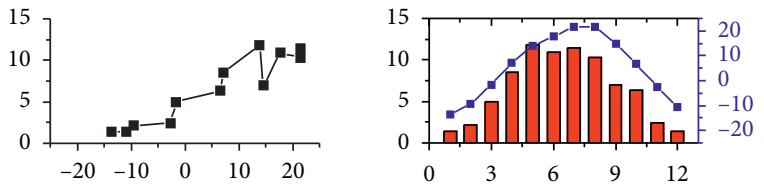

(3) YJ
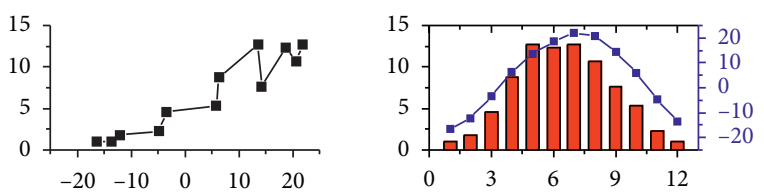

(5) JX
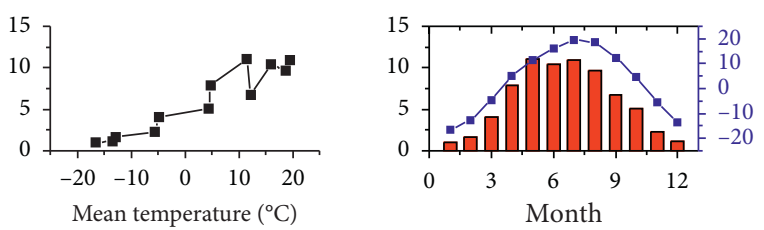

(7) $\mathrm{SFH}$

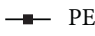

(a)

(b)
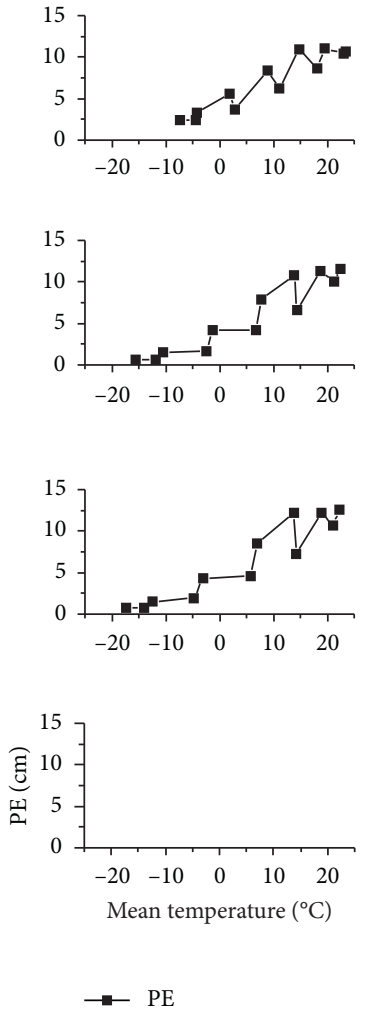

(a)

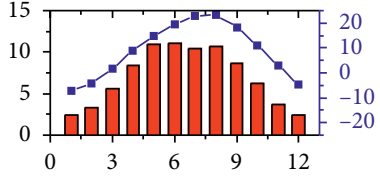

(2) DD

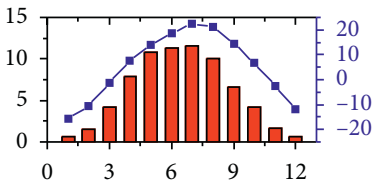

(4) LJ

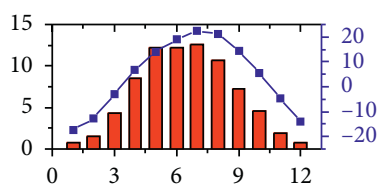

(6) MDJ

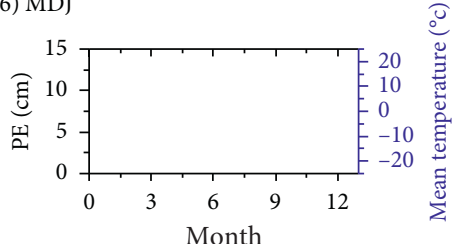

$\square$ PE

(b)

FIgURE 6: Correlation between the PE and mean temperature of seven reference meteorological stations. (a) PE as a function of mean temperature. (b) PE and mean temperature as a function of months.

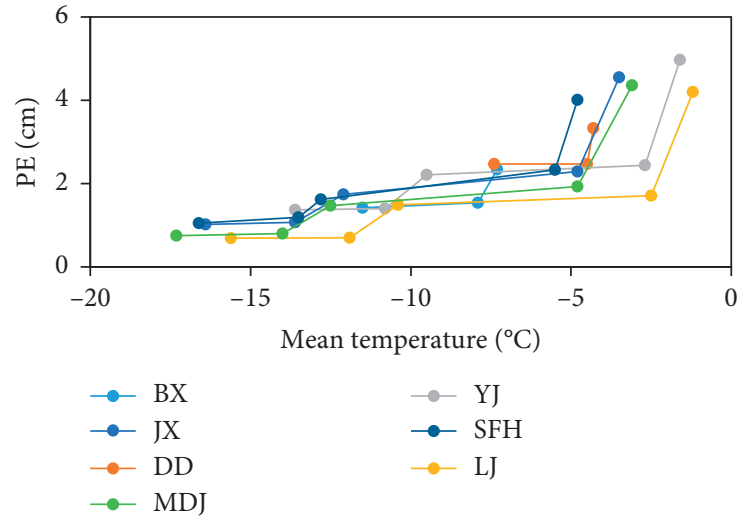

FIGURE 7: Relationship between PE and mean temperature below $0^{\circ} \mathrm{C}$.

TAble 9: Pearson correlation coefficient (mean temperature).

\begin{tabular}{|c|c|c|c|c|c|c|c|c|}
\hline & \multicolumn{7}{|c|}{ Meteorological station } & \multirow{2}{*}{ Mean value } \\
\hline & $\mathrm{BX}$ & $\mathrm{DD}$ & YJ & LJ & $\mathrm{JX}$ & MDJ & SFH & \\
\hline Analysis with annual temperature data & 0.93 & 0.94 & 0.94 & 0.94 & 0.94 & 0.94 & 0.95 & 0.94 \\
\hline Analysis with subzero temperature data & 0.70 & 0.56 & 0.82 & 0.82 & 0.87 & 0.85 & 0.88 & 0.79 \\
\hline
\end{tabular}

decreased significantly with increasing relative humidity, with an average rate of decrease of $0.23 \mathrm{~cm} / \%$ and an average correlation coefficient of -0.9 , as shown in Table 10 .
4.2. Accuracy of Potential Evapotranspiration (PE) Estimated with the FAO-56 PM Method. Figure 10 compares the results obtained with the FAO-56 PM and Thornthwaite methods to 


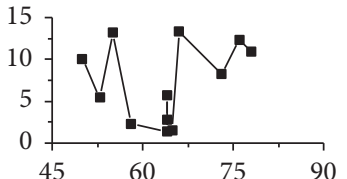

(1) $\mathrm{BX}$

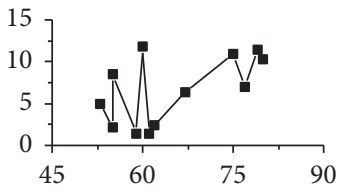

(3) $\mathrm{Y}$
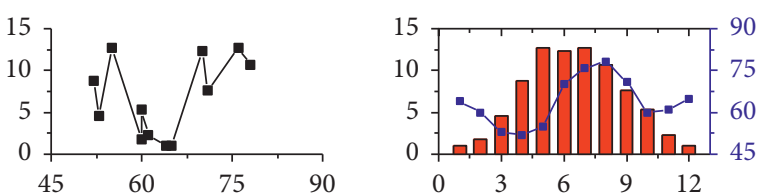

(5) JX
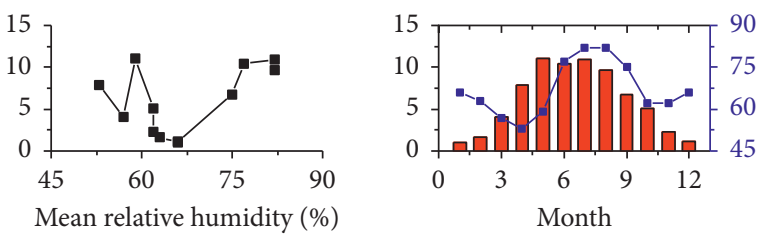

(7) $\mathrm{SFH}$

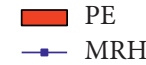

(b)
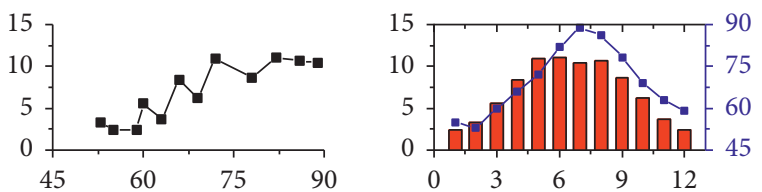

(2) DD
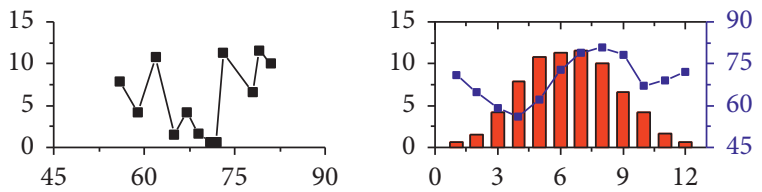

(4) L
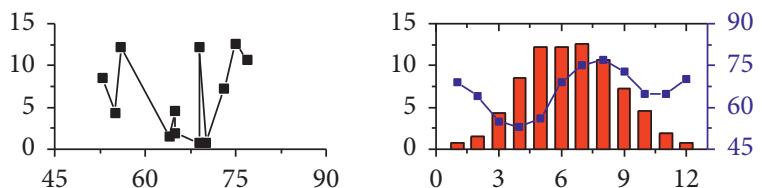

(6) MDJ
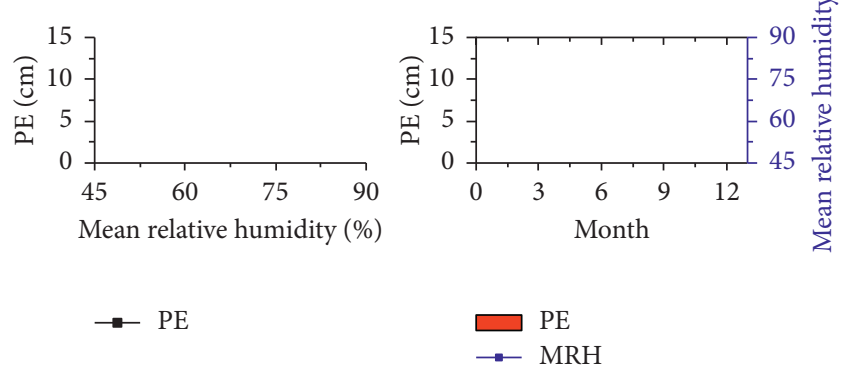

(a)

(b)

FIGURE 8: Correlation between the PE and mean relative humidity of seven reference meteorological stations. (a) PE as a function of mean relative humidity. (b) $\mathrm{PE}$ and mean relative humidity as a function of months.

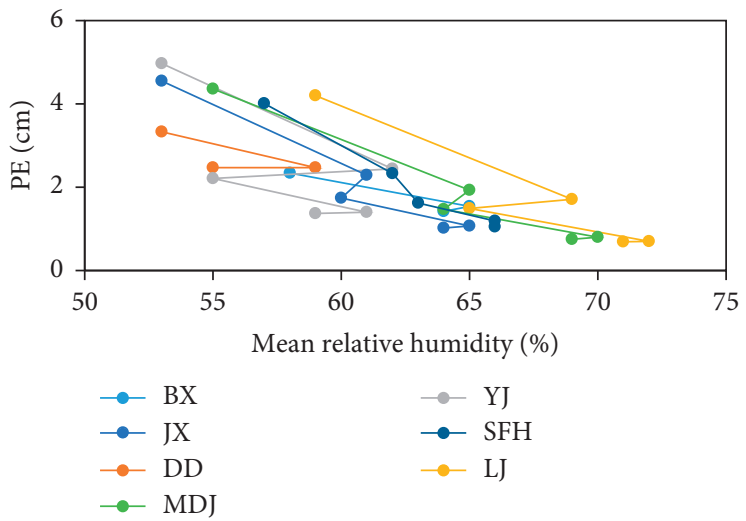

Figure 9: Relationship between PE and the mean relative humidity at subzero temperatures.

Table 10: Pearson correlation coefficient (mean relative humidity).

\begin{tabular}{lcccccccc}
\hline & \multicolumn{4}{c}{ Meteorological station } & \multicolumn{3}{c}{ Mean value } \\
& BX & DD & YJ & LJ & JX & MDJ & SFH & \\
\hline Analysis with annual temperature data & 0.19 & 0.89 & 0.57 & 0.23 & 0.33 & 0.10 & 0.43 & 0.39 \\
Analysis with subzero temperature data & -0.97 & -0.75 & -0.71 & -0.94 & -0.97 & -0.98 & -0.99 & -0.90 \\
\hline
\end{tabular}

the annual monthly evaporation (small) values (MSV) published by the China Meteorological Administration. The results indicate that the $\mathrm{PE}$ values calculated using the FAO56 PM method deviated slightly from the measured values but were consistent with the monthly trend. The estimated error range was $0.47-13.22 \mathrm{~cm}$, which was less than $12 \%$ of the total annual PE. In contrast, the PE values calculated using the Thornthwaite method greatly deviated from the 

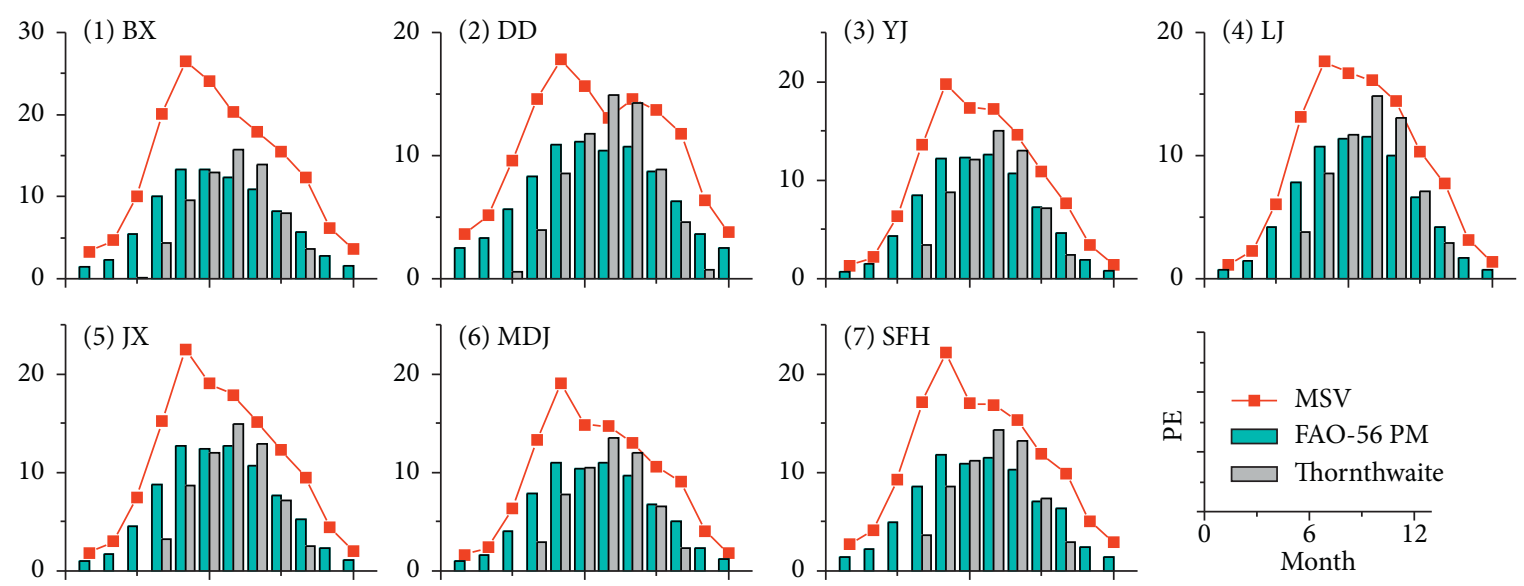

FIgURE 10: Comparison of PE with different estimation methods.

measured values. The winter PE was zero, and the annual peak appeared two months after the measured value. The estimated error range was $1.85-16.88 \mathrm{~cm}$, which was less than $15.3 \%$ of the total annual PE.

The FAO-56 PM method failed to accurately simulate the surge in PE between May and June. Although the calculated values increased, the increase was much less than those of the measured values. This difference occurred because the FAO-56 PM method used the mean temperature to directly calculate PE, instead of the maximum temperature. In Zone $\mathrm{II}_{1}$, the original meteorological data indicated a large temperature difference between day and night in May and June, and the mean temperature was often only approximately $65 \%$ of the maximum temperature. The mean temperature is an influencing factor that showed an extremely positive correlation with PE, which is why the calculated values of the model were less than the measured values.

4.3. Pavement Coverage Correction Coefficient. Table 11 presents the calculated $c$ values of the different soil classes at each station. The pavement coverage correction coefficient was greater than or equal to zero for the different soil classes at each station. Here, $c>1$ indicates that the subgrade had more moisture than the slope; thus, the moisture movement was from the subgrade to the slope. Meanwhile, $c<1$ indicated the opposite scenario.

\subsection{Subgrade Moisture Index $\left(I_{m}\right)$ Modified by the Pavement} Coverage Effect. The above calculation method was used to obtain the moisture balance, slope moisture index, and pavement coverage correction coefficient and to determine the moisture index of each station for different subgrade types. The results are presented in Table 12 .

The Chinese standard JTJ 003-1986 has been employed since 1986 and has contributed to the improvement of highway construction in China. In 2008, Wang et al. [33] studied the natural division of humid seasonally frozen regions in eastern China and further divided Zone $\mathrm{II}_{1}$ into four third-level zones: $\mathrm{II}_{1-a}, \mathrm{II}_{1-b}, \mathrm{II}_{1-c}$, and $\mathrm{II}_{1-d}$. Their thirdlevel zoning method combines a theoretical mathematical model and semiempirical correlation analysis to more objectively determine the boundaries. The seven meteorological stations in this study were scattered among Zone $\mathrm{II}_{1-a}$ (JX), Zone $\mathrm{II}_{1-b}(\mathrm{MDJ}$ and $\mathrm{SFH})$, Zone $\mathrm{II}_{1-c}(\mathrm{BX}, \mathrm{LJ}$, and $\mathrm{YJ})$, and Zone $\mathrm{II}_{1-d}$ (DD). Figure 11 compares the corrected values of the subgrade moisture index for the four third-level zones with the values based on current specifications along with the humidity coefficient $K$ :

$$
K=\frac{P}{P E} \text {. }
$$

The results indicate that $I_{\mathrm{m}}$ was $-14.2-0$ in Zone $\mathrm{II}_{1-\mathrm{a}}$, -1.1-0 in Zone $\mathrm{II}_{1-\mathrm{b}},-2.9-57.3$ in Zone $\mathrm{II}_{1-\mathrm{c}}$, and 25.7-48.5 in Zone $\mathrm{II}_{1-\mathrm{d}}$. The values gradually decreased from the southwest to the northeast. The average humidity coefficient was 0.67 in Zone $\mathrm{II}_{1-\mathrm{a}}, 0.72$ in Zone $\mathrm{II}_{1-\mathrm{b}}, 0.89$ in Zone $\mathrm{II}_{1-\mathrm{c}}$, and 1.10 in Zone $\mathrm{II}_{1-\mathrm{d}}$. The humidity coefficient gradually decreased from the southwest to the northeast. Zone $\mathrm{II}_{1}$ had minimum and maximum moisture index values of -14.2 and 57.3 , respectively; this range is slightly greater than that recommended by current specifications $(-8.1$ to 35.1$)$.

When the FAO-56 PM method was used to calculate the slope soil PE, the moisture index of the slope soil decreased because the $\mathrm{PE}$ at subzero temperatures was considered. The soil moisture index of the subgrade was obtained by using the pavement coverage correction coefficient to revise the slope moisture index $I_{\mathrm{m}}$. The range was not below that of the values recommended by the current code; however, the maximum and minimum values produced a wider range. The four third-level zones in Zone $\mathrm{II}_{1}$ showed clear differences in the subgrade moisture index. In particular, Zone $\mathrm{II}_{1 \text { - }}$ ${ }_{c}$ had the widest range for the subgrade moisture index of -2.9 to 57.3 . This zone had a wider range than $Z_{\text {Zone }} \mathrm{II}_{1-\mathrm{d}}$ and a greater maximum value. This can be explained by the natural geographical environment of Zone $\mathrm{II}_{1-c}$, which is dominated by the core area of the Changbai Mountain Nature Reserve and contains 16 peaks that are $2500 \mathrm{~m}$ above sea level. The annual sunshine hours are less than $2300 \mathrm{~h}$, and the evapotranspiration capacity is relatively weak. In addition, the annual precipitation in this area is between 700 and 
TABLE 11: $c$ of different soil types in Zone $\mathrm{II}_{1}$.

\begin{tabular}{|c|c|c|c|c|c|c|c|}
\hline \multirow{2}{*}{ Soil group } & \multicolumn{7}{|c|}{ Meteorological station } \\
\hline & $\mathrm{BX}$ & DD & YJ & LJ & JX & MDJ & SFH \\
\hline Sand & 0.01 & 1.46 & 0.38 & 25.80 & 1.04 & 0.22 & 0 \\
\hline Other sandy soils & 0 & 1.15 & 0 & 6.82 & 0 & 0 & 0 \\
\hline Powdery soil & 0 & 30.57 & 0.06 & 0 & 0.13 & 0 & 0 \\
\hline Clayey soil & 0 & 1.22 & 0 & 2.71 & 0 & 0 & 0 \\
\hline
\end{tabular}

TABLE 12: $I_{m}$ of different soil types of Zone $\mathrm{II}_{1}(\mathrm{~cm})$.

\begin{tabular}{|c|c|c|c|c|c|c|c|}
\hline \multirow{2}{*}{ Soil group } & \multicolumn{7}{|c|}{ Meteorological station } \\
\hline & BX & $\mathrm{DD}$ & YJ & LJ & JX & MDJ & $\mathrm{SFH}$ \\
\hline Sand & -0.003 & 25.7 & -2.9 & 30.4 & -14.2 & -1.1 & 0 \\
\hline Other sandy soils & 0 & 28.6 & 0 & 33.7 & 0 & 0 & 0 \\
\hline Powdery soil & 0 & 40.0 & 0.1 & 0 & -0.6 & 0 & 0 \\
\hline Clayey soil & 0 & 48.5 & 0 & 57.3 & 0 & 0 & 0 \\
\hline
\end{tabular}

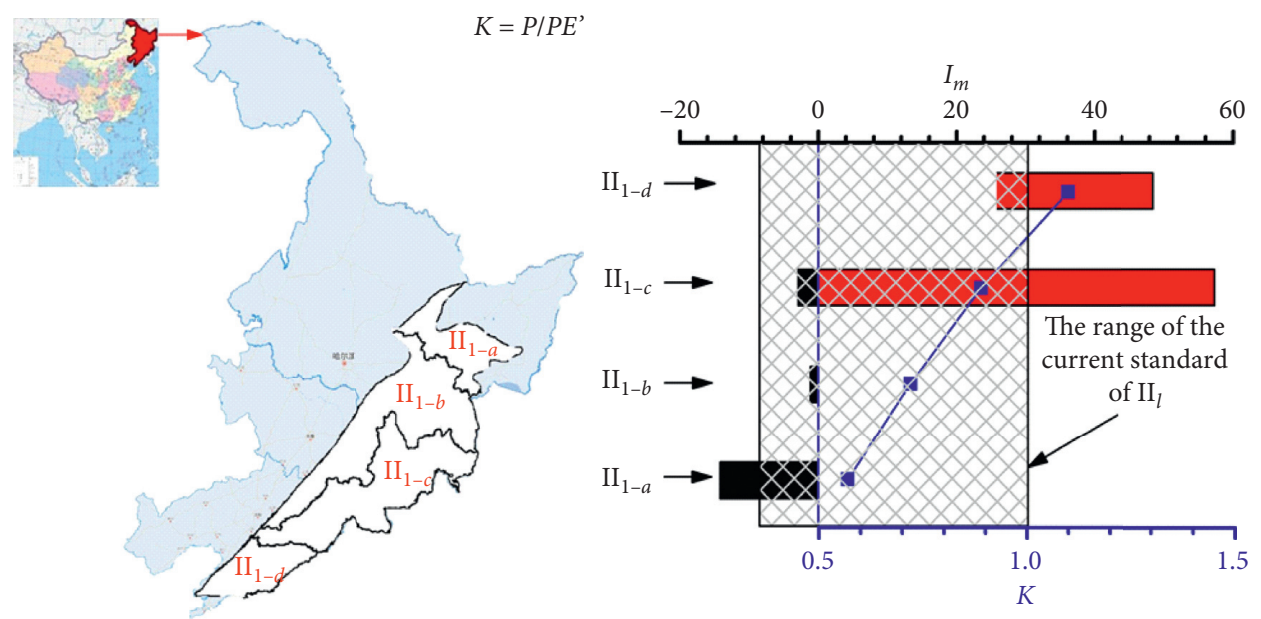

FIGURE 11: Comparisons of the ranges of subgrade moisture index for Zone $\mathrm{II}_{1}$ obtained by different methods. (a) The geographical location of zone $\mathrm{II}_{1}$. (b) Coefficient (K).

$1400 \mathrm{~mm}$; thus, the surface runoff is high and leads to a high moisture index.

To summarize, the third-level zoning method was used to refine the subgrade moisture index in Zone $\mathrm{II}_{1}$ to distinguish the different influences of the climate, geological landforms, and other factors. This method was shown to be effective at improving the calculation accuracy of the subgrade moisture index.

\section{Conclusion}

Taking into account the nonnegligible evapotranspiration at subzero temperatures and the pavement coverage effect, we presented an improved method for calculating the moisture index of subgrade in seasonally frozen regions. The FAO-56 PM method was applied to estimate the PE at subzero temperatures, which is neglected by the Thornthwaite method, to calculate the moisture index of an uncovered slope. The PE was found to account for $9.8 \%-15.7 \%$ of the total annual evapotranspiration. Based on the relationship between the matric suction and soil water content, a correction coefficient was proposed to define the pavement coverage effect. In accordance with this effect, an optimized moisture calculation formula without considering the source of the evaporated water was developed to map the moisture index of the uncovered slope to that of the covered subgrade. The results of a case study demonstrated the validity of the proposed method in determining the subgrade moisture index of seasonally frozen regions, whose reasonable range appears to be -14.2 to 57.3 for subgrade design. This study can not only aid systematically elucidating the formation pattern of subgrade moisture in seasonally frozen regions but also shed some light on the design and operation management implications of highway subgrade to improve their operational performance. Future studies that consider the effect of ice condensation and bidirectional melting are required to further improve the subgrade moisture calculation approach.

\section{Data Availability}

All data, models, and code generated or used during the study appear in the submitted article. 


\section{Conflicts of Interest}

The authors declare that there are no conflicts of interest regarding the publication of this paper.

\section{Acknowledgments}

This research was supported by the National Natural Science Foundation of China (51908095).

\section{References}

[1] Y. Perera, C. Zapata, W. N. Houston, and S. L. Houston, "Long-term moisture conditions under highway pavements," in Proceedings of the GeoTrans 2004, pp. 1132-1143, ASCE, Los Angeles, CA, USA, July 2004.

[2] J. Xu, M. Zhang, Y. Li, and Z. Wu, "Experimental study on deterioration behavior of saline undisturbed loess with sodium sulphate under freeze-thaw action," Chinese Journal of Geotechnical Engineering, vol. 42, no. 9, pp. 1642-1650, 2020.

[3] G. D. Aitchison and B. G. Richards, "A broad-scale study of moisture conditions in pavement subgrades throughout Australia," Moisture Equilibria and Moisture Changes in Soil beneath Covered Areas, pp. 184-232, Butterworths, Sydney, Australia, 1965.

[4] A. A. Basma and T. I. Al-Suleiman, "Climatic considerations in new AASHTO flexible pavement design," Journal of Transportation Engineering, vol. 117, no. 2, pp. 210-223, 1991.

[5] J. Ling, B. Han, Y. Xie, Q. Dong, Y. Sun, and B. Huang, "Laboratory and field study of electroosmosis dewatering for pavement subgrade soil," Journal of Cold Regions Engineering, vol. 31, no. 4, Article ID 04017010, 2017.

[6] JTG D30-2015, Specification for Design of Highway Subgrade, China Communications Press, Beijing, China, 2015.

[7] C. W. Thornthwaite, "An approach toward a rational classification of climate," Geographical Review, vol. 38, no. 1, pp. 55-94, 1948

[8] V. V. Bhaskar, "Hydro-climatic characteristics of hill stations of India," Meteorology \& Atmospheric Sciences, vol. 66, no. 1, pp. 129-138, 2015.

[9] A. Zareie, M. S. R. Amin, and L. E. Amador-Jimenez, "Thornthwaite moisture index modeling to estimate the implication of climate change on pavement deterioration," Journal of Transportation Engineering, vol. 142, no. 4, Article ID 04016007, 2016.

[10] H. Chang, "The potential evapotranspiration (PE) index for vegetation and vegetation-climatic classification (2) - an introduction of main methods and PEP program," Acta Phytoecologica et Geobotanica Sinica, vol. 13, no. 3, pp. 197-207, 1989.

[11] H. Li, D. Guan, C. Jin, A. Wang, F. Yuan, and J. Wu, "Measurement and estimation methods and research progress of snow evaporation in forests," Chinese Journal of Applied Ecology, vol. 24, no. 12, pp. 3603-3609, 2013.

[12] E. Christner, M. Kohler, and M. Schneider, "The influence of snow sublimation and meltwater evaporation on," Atmospheric Chemistry and Physics, vol. 17, no. 2, pp. 1207-1225, 2017.

[13] Q. Yang, Study on Spatio-Temporal Distribution of Snow Cover in Northeast China and its Simulation on Snowmelt Runoff, Jilin University, Changchun, China, 2015.

[14] J. Xu, S. Peng, J. Ding, and Z. Wei, "Evaluation of methods for estimation daily reference crop evapotranspiration based on lysimetric grass experiments," Shuili Xuebao, vol. 41, no. 12, pp. 1497-1505, 2010.

[15] K. Feng and J. Tian, "Estimation of evapotranspiration in Ningxia by Hargreaves equation," Journal of Arid Land Resources and Environment, vol. 28, no. 9, pp. 100-105, 2014.

[16] R. G. McKeen and L. D. Johnson, "Climate-controlled soil design parameters for mat foundations," Journal of Geotechnical Engineering, vol. 116, no. 7, pp. 1073-1094, 1990.

[17] L. Sun and Z. Chen, "Estimation of regional evapotranspiration based on Penman-Monteith equation and soil moisture index," Transactions of the Chinese Society of Agricultural Engineering, vol. 29, no. 10, pp. 101-295, 2013.

[18] L. Zhao and W. Zhao, "Evapotranspiration of an oasis-desert transition zone in the middle stream of Heihe River, Northwest China," Journal of Arid Land, vol. 6, no. 5, pp. 529-539, 2014.

[19] JTJ 003-1986, Standard of Climatic Zoning for Highway, China Communications Press, Beijing, China, 1986.

[20] Y. Li, S. Jiao, Y. Bao et al., "Dry and wet state discrimination and the application model on the road surface of expressway," Chinese Journal of Tropical Meteorology, vol. 33, no. 4, pp. 558-567, 2017.

[21] X. Liu and L. Sun, "Effects of environmental factors on pavement performance in distress," Chinese Journal of Tongji University, vol. 24, no. 4, pp. 398-404, 1996.

[22] X. Qiu, Q. Yang, and Q. You, "Distribution characteristics and prediction of equilibrium moisture of non-saturated clay subgrade," Journal of Chongqing Jianzhu University, vol. 35, no. 2, pp. 15-20, 2013.

[23] J. Ling, S. Lin, J. Qian, J. Zhang, B. Han, and M. Liu, "Continuous compaction control technology for granite residual subgrade compaction," Journal of Materials in Civil Engineering, vol. 30, no. 12, 2018.

[24] W. Ran and L. Li, "Distribution and prediction of equilibrium moisture of subgrade considering pavement blanketing effect," Journal of Chongqing Jiaotong University (Natural Science), vol. 34, no. 6, pp. 58-62, 2015.

[25] G. Li, Advanced Soil Mechanics, Science Press, Beijing, China, 2004.

[26] J. Zhou, Dictionary of Soil Science, Science Press, Beijing, China, 2013.

[27] S. Tian, P. Tregoning, L. J. Renzullo et al., "Improved water balance component estimates through joint assimilation of GRACE water storage and SMOS soil moisture retrievals," Water Resources Research, vol. 53, no. 3, pp. 1820-1840, 2017.

[28] D. Li, C. Sun, and X. Zhang, "Modelling the net primary productivity of the natural potential vegetation in China," Journal of Integrative Plant Biology, vol. 40, no. 6, pp. 77-83, 1998.

[29] A. H. Javid and R. Bulut, "Evaluating equilibrium matric suctions under pavement system based on Thornthwaite moisture index (TMI)," in Airfield and Highway Pavements 2019: Testing and Characterization of Pavement Materials, pp. 511-521, ASCE, Reston, VA, USA, 2019.

[30] S. Saha, N. Hariharan, F. Gu et al., "Development of a mechanistic-empirical model to predict equilibrium suction for subgrade soil," Journal of Hydrology, vol. 575, pp. 221-233, 2019.

[31] W. Zou, C. Li, J.-F. Wang, W.-D. Deng, and Z. Wang, "Model tests on responses of unsaturated road-embankments to loading and rainfall infiltration," Chinese Journal of Geotechnical Engineering, vol. 31, no. 10, pp. 1512-1519, 2009. 
[32] C. Li, J. Ling, and S. Guan, "Prediction-based subgrade moisture Thornthwaite moisture index," Journal of Tongji University (Natural Science), vol. 40, no. 11, pp. 1672-1676, 2012.

[33] C.-X. Wang, Z.-Y. Ma, D.-C. Feng, and H. Luan, "Method of the third rank division of highway in east seasonal frost region," Chinese Journal of Harbin Institute of Technology, vol. 40, no. 2, pp. 250-254, 2008. 